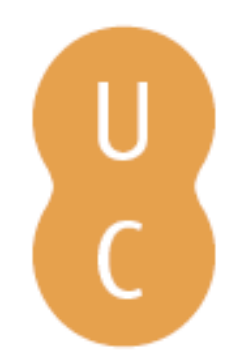

\title{
pommalina
}

\section{Paisagem literária: imanência e transcendência}

\author{
Autor(es): $\quad$ Buescu, Helena Carvalhão
}

Publicado por: Imprensa da Universidade de Coimbra

URL

persistente:

URI:http://hdl.handle.net/10316.2/38688

DOI:

DOI:http://dx.doi.org/10.14195/978-989-26-1164-8_11

Accessed : $\quad$ 26-Apr-2023 11:17:16

A navegação consulta e descarregamento dos títulos inseridos nas Bibliotecas Digitais UC Digitalis, UC Pombalina e UC Impactum, pressupõem a aceitação plena e sem reservas dos Termos e Condições de Uso destas Bibliotecas Digitais, disponíveis em https://digitalis.uc.pt/pt-pt/termos.

Conforme exposto nos referidos Termos e Condições de Uso, o descarregamento de títulos de acesso restrito requer uma licença válida de autorização devendo o utilizador aceder ao(s) documento(s) a partir de um endereço de IP da instituição detentora da supramencionada licença.

Ao utilizador é apenas permitido o descarregamento para uso pessoal, pelo que o emprego do(s) título(s) descarregado(s) para outro fim, designadamente comercial, carece de autorização do respetivo autor ou editor da obra.

Na medida em que todas as obras da UC Digitalis se encontram protegidas pelo Código do Direito de Autor e Direitos Conexos e demais legislação aplicável, toda a cópia, parcial ou total, deste documento, nos casos em que é legalmente admitida, deverá conter ou fazer-se acompanhar por este aviso.

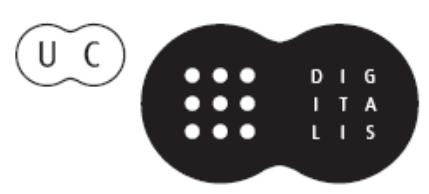


Helena Carvalhão Buescu

Universidade de Lisboa / Centro de Estudos Comparatistas

\section{PAISAGEM LITERÁRIA: IMANÊNCIA E TRANSCENDÊNCIA}

A hipótese de que parto é a de que a paisagem literária constitui uma das mais interessantes manifestações da natureza histórica do lugar, bem assim da forma como este reflecte e configura as relações do humano com o que imagina enquanto transcendente. A paisagem é uma forma de evidência do lugar que está longe de se confinar a uma visão idílica dos seus componentes. Como veremos, a sua fundamentação estética (e por isso histórico-cultural), enquanto conceito, faz parte da sua mesma natureza, resultando num complexo feixe de relações que está bem longe daquilo que no senso comum define o carácter da paisagem como o que apenas "está aî". Uma paisagem nunca se limita a "estar aî". Ela constitui-se como um acontecimento que o sujeito constrói na história. É pois este o conjunto de questões que pretendo aqui desenvolver.

Explico também porque me atenho mais a uma reflexão historicamente mais aproximada de nós. É que o termo e o conceito de paisagem são de formação relativamente recente (cf. Buescu, 1990). Significa isto que eles reflectem uma experiência do mundo dentro da história, e que a ideia de natureza que manifestam é tudo menos simples. Na realidade, quer o termo quer o conceito de paisagem (as primeiras atestações são paesaggio em italiano, landschap em neerlandês, de onde passa para o inglês) surgem pela primeira vez no século xvi. São respectivamente de 1549 (Robert Estienne) e de 1552 (Tiziano) as primeiras definições de paisagem como uma conformação de um objecto cultural: "Representação pictórica de uma vista, normalmente como fundo de um quadro", diz Estienne. É pois fundador o seu carácter estético, na medida em que a paisagem parece surgir, em primeiro lugar, como uma relação com um objecto pictórico, 
apenas mais tarde transposta para a apreensão de natureza como experiência directa. Não é por acaso que é em italiano e em neerlandês que os termos primeiramente surgem, numa clara relação com a pintura italiana e flamenga, respectivamente. Paul Valéry dizia, de modo expressivo, que a paisagem está para a natureza como a ópera está para o "comum da vida".

Em segundo lugar, essa relação envolve a organização do espaço perceptivo, implicando, explícita ou implicitamente, a existência de um sujeito capaz de "ver" de modo estruturado, e de perceber o que vê como uma forma com sentido. Essa apreensão do espaço é realizada através de uma posição (pontualmente) fixa, colocando o sujeito dentro da representação que é feita do espaço, mesmo quando o sujeito dele parece estar ausente. Esta posição deriva de uma outra construção pictórica, feita de modo gradual e lento na passagem da Idade Média para o Renascimento: a noção de perspectiva (cf. Francastel, 1977 e Panofsky, 1975), realizada ao longo do Quattrocento e reflectindo a representação visual de um espaço euclidiano e geométrico. A pressuposição da noção de perspectiva arrasta consigo algumas consequências, para lá das óbvias implicações pictóricas que tem. Permito-me ficar aqui por aquelas que derivam do próprio étimo de "perspicere", que significa, em latim, "ver através de". Trata-se pois de uma representação dos objectos e das suas inter-relações, nomeadamente volumétricas e tridimensionais, numa superfície plana e bidimensional; e de uma representação da distância relativa quer entre esses mesmos objectos quer face ao sujeito observador.

Em terceiro lugar, o conceito de paisagem (também literária) implica o exercício do olhar sobre um todo heterogéneo, constituído não por objectos avulsos justapostos mas, pelo contrário, pelas relações irregulares de um conjunto de elementos. A noção de irregularidade, complementar da de simetria, é aqui também decisiva: trata-se de ver um conjunto de objectos, preferencialmente captados por uma direcção oblíqua e por um sentido ascendente/descendente desse olhar. A paisagem, literal ou metafórica, chega assim ao século xıx como "pan-orama" (termo aliás oitocentista): tudo aquilo que se vê. Trata-se assim de um espaço humanizado, pelo olhar, pela habitação vivencial e pela habitação estética. É este espaço humanizado, apreensível através do conceito de paisagem literal ou de paisagem metafórica, como disse, que pretendo aqui analisar, em alguns exemplos provenientes da literatura portuguesa. 
Começo justamente por um exemplo desse carácter metafórico, que permite captar (e por isso olhar para) o passado como paisagem, um lugar constituído através da relação entre os objectos captados, na sua diferença e irregularidade, e através da relação que eles mantêm com o sujeito. Não surpreenderá perceber que o lugar da infância é, sobretudo desde Baudelaire, uma das formas que essa paisagem do passado pode tomar. Dizia Baudelaire (1): "Mas o verde jardim dos amores infantis,/ O ingénuo paraíso dos prazeres furtivos/ Tornou-se mais distante que a Índia e a China?" ("Moesta et errabunda", 175). Ora, é esta distância que a infância, tomada como paisagem metafórica, como lugar apreendido pelo sujeito que a contempla, pode manifestar. No poema de Álvaro de Campos, "Anniversario" (p. 217) (2), é a "casa" da infância que visualmente congrega essa paisagem irregular que a perspectiva do presente permite contemplar: uma paisagem como história do homem, em que a "casa antiga" se dá a ver como uma "mesa" com "mais lugares, melhores desenhos na louça, mais copos", um "aparador com muitas coisas - doces, frutas, o resto na sombra debaixo do alçado"; e em que a oposição entre a felicidade do passado e a infelicidade do presente é visualmente expressa pela diferença entre a casa antiga, por um lado, e "a humidade no corredor do fim da casa/, Pondo grelado nas paredes", por outro. É por isso que o sujeito, vendo duas paisagens, não consegue conciliá-las a partir de uma só perspectiva: é o passado que cega o presente ("Vejo tudo outra vez com uma nitidez que me cega para o que há aqui”). Trata-se pois de ver a história como uma espécie de contra-utopia, em que a noção de perda associada ao presente surge, de qualquer forma, como garante de que em algum momento - e lugar - do passado essa utopia da plenitude existiu. É por isso que George Eliot (3), num belíssimo romance que Álvaro de Campos, se não conheceu directamente através de Pessoa, teria compreendido, fala das "cicatrizes" que a paisagem conserva: "Para os olhos que viveram nesse passado não há reparação completa".

A consciência do tempo perdido manifesta-se assim através da consciência do espaço, do lugar perdido, aqui residindo também o problema da transcendência como visibilidade de uma perda: o próprio do Paraíso é ter sido perdido pelo homem. Ora esta questão arrasta consigo uma outra pergunta decisiva, sobre onde encontrar a sede do sentido. A resposta transcendente, que de certa forma Baudelaire e Campos ainda marginalmente acolhem, consiste em fazer 
reflectir no "lado de lá" (a infância) esse sentido inatingível e portanto de certa forma utópico.

O curioso é que um dos (vários) paradoxos da construção da modernidade (lato sensu) reside na irrupção da prática sistemática da paisagem como lugar-no-mundo, como hipótese de uma imanência. Esta simultaneidade não é, no entanto, casual. Pelo contrário, ela exprime que a paisagem literária, surgindo de forma consistente na literatura sobretudo a partir do século xviı, nasce sobretudo do confronto e da consciência de que também a paisagem se perde. A literatura alimenta-se da paisagem no momento em que, com a Revolução Industrial, esta parece estar irremediavelmente ferida, e por isso em brusco desaparecimento. Tal consciência do carácter precário da natureza, da sua historicidade (afinal humana) faz parte da noção de paisagem e acompanha, de uma forma ou de outra, as suas variadíssimas manifestações. Sublinhemos desde já que tal só pode acontecer porque a paisagem é sempre humanizada, e porque através dela se interroga o lugar do sujeito/homem: onde, a que pertencemos?

O Romantismo vai respondendo a estas perguntas através da manifestação de transcendências que conseguem ainda manifestar-se como imanências, posições, localizações no mundo: por exemplo a história, o nacionalismo, ou a identidade. O exemplo que se segue é de Almeida Garrett, no cap. 42 de Viagens na Minha Terra (4).

[...] em verdade não sei explicar a impressão que me faz uma ruína neste estado. Desafinam-me os nervos, vibram-me numa discordância e dissonância insuportável. Queria ver antes estes altares expostos às chuvas e aos ventos do céu, - que o sol os queimasse de dia, - que à noite, à luz branca da lua, ou ao tíbio reflexo das estrelas, piasse o mocho e sussurrasse a coruja sobre seus arcos meio caídos.

Não me parecia profanado o tempo assim, nem descaído de majestade o monumento. Podia ajoelhar-me no meio das pedras soltas, entre as ervas húmidas, e levantar o meu pensamento a Deus, o meu coração à glória, à grandeza, o meu espírito às sublimes aspirações da idealidade. O material, o grosseiro, o pesado da vida não me vinham afligir aí.

Deus, a ideia grande do mundo - Deus, a Razão Eterna - Deus, o amor, Deus, a glória - Deus, a força, a poesia e a nobreza d'alma - Deus está nas 
ruínas escalavradas do Coliseu, como nos zimbórios de bronze e mármore de S. Pedro.

Mas aqui!... nos pardeiros de um convento velho, consertado pelas Obras-públicas para servir de quartel de soldados - aqui não habita espírito nenhum.

Quero-me ir embora daqui! (p. 406)

Trata-se de um excerto onde são confrontados dois tipos de ruínas: aquelas que manifestam o espírito do lugar, o famoso genius loci romântico, e em que, por isso, "Deus, a ideia grande do mundo - Deus, a Razão Eterna - Deus, o amor - Deus, a força, a poesia e a nobreza da alma”, pode habitar; e, por outro lado, aqueloutras ruínas onde só existe a rasteira materialidade da burocracia moderna, e onde por isso, segundo Garrett, "não habita espírito nenhum”. O desaparecimento do espírito do lugar é um esvaziamento de sentido da paisagem, de qualquer paisagem - um encapsulamento da matéria na matéria que a literatura vai progressivamente deixando de poder perscrutar. Foi a isto que eu chamei "a construção da escuridão na modernidade" (Buescu, 2001). Aquilo que nós aqui encontramos é precisamente a suspeita de que a paisagem vai perdendo a sua capacidade de manifestar o transcendente, e de que os valores correspondentes ao "quartel de soldados" podem vir a ser os predominantes no mundo contemporâneo, aliás ecoando os "barões" e os "deputados" de que Garrett se sentia tão distante. Um mundo ocupado pelos valores apenas materiais, e onde nenhum espírito habita, é um mundo de onde a paisagem desaparece, e onde o lugar humano deixa de existir.

Por isso, ao lado da consciência do lugar manifestada por Garrett surge também uma presença mais forte do exílio, que explora as intermitências do conceito de fronteira enquanto, por um lado, bloqueio, fechamento e segregação; e, por outro, passagem, transição e permeabilidade. De um lado, temos um cosmos organizado, às vezes demasiado organizado, que exprime a divisão entre espaços e assegura, simultaneamente, segurança e fechamento. Do outro, um caos sempre potencialmente ameaçador e invasivo, mas garante, por seu turno, de ritos de passagem e, por isso, de mudança. Uma hipótese de solução para esta intermitência é a encontrada por Alexandre Herculano (5): o lá está $a q u i$, e pode ser reconhecido sob figurações que o Poeta singularmente apreende para poder, depois, transmitir. 
Eis o ruído do ermo! Ao longe o negro,

Insondado oceano, e o céu cerúleo

Se abraçam no horizonte. Imensa imagem

Da eternidade e do infinito, salve!

(“A Arrábida”, p. 76)

A paisagem é aqui o lugar em que o Poeta, já conscientemente exilado neste lugar, pode apesar de tudo reconhecer essa outra "imensa imagem da eternidade e do infinito", dirigindo-se a ela e, ainda "falando" com ela: "salve!". A coincidência entre a dimensão física da paisagem e as dimensões axiológica e metafísica é decisiva para Herculano, para quem o mundo, todo o mundo, é passível de descrição através da consciência dos valores absolutos que o estruturavam. Diferentemente de Herculano, para quem o lá está aqui, vários anos mais tarde, na viragem do século xix para o século xx, António Nobre (6) tornava-se um dos vários exilados de lá, para quem "o tempo que lá vai" apresenta a substância forte que o presente já não parece possuir:

Às vezes, passo horas inteiras

Olhos fitos nestas braseiras,

Sonhando o tempo que lá vai;

E jornadeio em fantasia

Essas jornadas que eu fazia

Ao velho Douro, mais meu Pai.

("Viagens na minha terra", p. 74)

O próprio facto de Nobre repetir o título de Garrett evidencia a distância que os separa, ao mesmo tempo que a consciência do lugar que os aproxima. Seja como for, em Nobre existe um lugar que continua seguro, mesmo se longe ou até inatingível: é esse lugar que assegura a fundação do sujeito. O facto de as actividades que permitem aceder a ele serem o sonho, a fantasia e a contemplação não lhe retira espessura simbólica, pelo contrário.

Outros dois autores, um escrevendo alguns anos antes de Nobre, outro alguns anos depois, manifestam entretanto a mesma consciência da paisagem como materialidade transcendente, embora com uma dimensão de perturbação 
que parece já irremediável, e que julgo caracterizar, em grande medida, toda a posterior experiência novecentista da paisagem literária. Refiro-me a Antero de Quental (7), por um lado; e a Raul Brandão (8), por outro. No primeiro, o soneto "Oceano Nox" constitui um dos altos lugares em que sujeito e paisagem se confrontam, como duas entidades paralelamente questionantes e perturbadas, que parecem tentar falar uma com a outra, sem todavia o conseguirem: o poeta e o mar, face a face, partilham aquilo a que o poema chamará, de forma significativa, uma "trágica voz rouca":

Junto do mar, que erguia gravemente

A trágica voz rouca, enquanto o vento

Passava como o voo dum pensamento

Que busca e hesita, inquieto e intermitente,

Junto do mar sentei-me tristemente,

Olhando o céu pesado e nevoento,

E interroguei, cismando, esse lamento

Que saía das cousas, vagamente...

Que inquieto desejo vos tortura,

Seres elementares, força obscura?

Em volta de que ideia gravitais? -

Mas na imensa extensão, onde se esconde

O Inconsciente imortal, só me responde

Um bramido, um queixume, e nada mais...

("Oceano Nox", p. 155)

Não se trata aqui de considerar que os sentimentos do sujeito se reflectem na paisagem. É mais do que isso. Ambos apresentam um estado de "inquietação" essencial, uma vontade incipiente de falar que não consegue alcançar formas articuladas de linguagem, e que se fica por "esse lamento/ que saía das cousas, vagamente", ou por "um bramido, um queixume, e nada mais...". O poeta, que pretendia ouvir a voz da natureza, estruturada e manifestada na paisagem, 
é assim confrontado com murmúrios infra-humanos que ele não consegue compreender. A sua inquietação só poderá desembocar no silêncio, que para Antero tomará cada vez mais a forma da morte. Deus torna-se cada vez mais o Deus absconditus, retirado e mudo, e a paisagem cada vez mais também aquilo que não pode aceder ao sentido.

Este carácter misterioso e insondável que ataca e mina a paisagem, e que nela escreve o mistério da consciência (e a que Alberto Caeiro dará a sua voz maior de mestre, por denegação) toma, em Raul Brandão, particularmente nas suas Ilhas Desconhecidas, as formas preferenciais capazes de dar conta de uma caoticização da paisagem que corresponde a uma infernalização do mundo. Não é preciso sair do mundo para encontrar o Inferno, como um pouco mais tarde o escritor existencialista Jean-Paul Sartre lembrava, ao clamar "L'Enfer, c'est les autres". O poder destruidor da transcendência, do lado de lá, é transportado por Brandão para a imanência, o lado de cá. A paisagem é o lugar simbólico por excelência onde os poderes de violência e do caos se exprimem, escolhendo para tal formulações afins da estética do grotesco e do expressionismo, e por isso são as sensações, já não garante de estabilidade mas pelo contrário portadoras de distorção, que melhor se aproximam desse mundo deformado:

[...] As estrelas nos ares agitados parecem outras estrelas, o céu outro céu e as forças desencadeadas do caos nunca as senti tão perto como hoje, nesta voz monótona que sai do negrume, nesta massa que nos mostra os dentes no alto das vagas entre as chapadas de tinta na imensa solidão desolada. Isto acaba pela treva absoluta. Está ali - está presente toda a noite que não tem fim. Nós bem fingimos que não vemos a solidão trágica, o negrume trágico, mas eu tenho-o toda a noite ao pé de mim. Toda a noite esta coisa complicada que é um transporte a vapor range pavorosamente como se fosse desconjuntar-se; toda a noite sinto a água bater no costado e a máquina pulsar contra meu peito. A ideia da morte não nos larga: separa-nos do caos um tabique de não sei quantas polegadas. Todos os passageiros se fingem despreocupados. Só acolá, sob o castelo da proa ( $3^{\text {a }}$ classe), embrulhada num xale e sentada sobre um baú de lata, aquela mulher do povo sente como eu o terror sagrado do mar - e não o oculta. Olha petrificada. Aqui só há uma coisa a fazer, é a gente entregar-se... (p. 10) 
A coisificação do mundo, expressa pela repetição do pronome neutro "isto", ou pela expressão "esta coisa”, está já completa em Brandão. E não é por acaso que o adjectivo que lhe ocorre, para exprimir a força do caos e a certeza da ausência de sentido que a viagem marítima confirma, é o adjectivo "trágico": "a solidão trágica, o negrume trágico". Aquilo que em Antero assumia ainda a forma de uma "inquietação", e de uma fala incompreensível, torna-se aqui num "terror sagrado" (do mar, do mundo e da morte).

Terminarei com um exemplo simétrico daquele com que comecei, mas que dá já bem conta de como o espaço histórico que separa Álvaro de Campos, ainda herdeiro de Baudelaire, e Carlos de Oliveira, que vem nomeadamente depois (no sentido forte) de Raul Brandão, é já bem grande. Esse espaço histórico exprime-se também em Carlos de Oliveira através do lugar metafórico da casa, inserida numa paisagem dunar e minada à partida, e onde a perda não é exercida de fora para dentro, mas pelo contrário a partir do próprio dentro. Em Campos, como em Baudelaire, a paisagem do passado parecia poder ser plena como um Paraíso perdido. Em Carlos de Oliveira, a casa e a família são construídas sobre dunas, espaços intersticiais incapazes de oferecer solidez a qualquer raiz que sobre elas se queira estabelecer, espaços intersticiais que escondem outras realidades, outros mundos desconhecidos, fruto daquilo a que Carlos de Oliveira chamará também "cataclismos".

Os terrenos hoje agricultados, onde a família construiu a casa de adobos (que as cantarias, os cunhais de pedra, têm aguentado), eram dantes extensões maninhas, eriçadas de felga e gramata. Em tempos ainda mais recuados, uma flora gigantesca cobriu a região: encontra-se enterrada ao nível do mar e abaixo dele. Árvores de grande altura, entre dois lençóis de areia branca. Madeiras fibrosas, duras, de cor geralmente vermelha. Veios de barro e argila: azuis, verdes, encarnados. A combustão destas madeiras (descobertas em escavações de acaso) é lenta e sem chama como a do carvão. Durmo sobre florestas de pedra e púrpura. (p. 1053)

A progressão de distância histórica aqui expressa por "hoje", "dantes" e "em tempos ainda mais recuados" exprime a consciência de uma paisagem estratificada que responde àquilo que eram, em George Eliot, as "cicatrizes" da paisagem. Mas em Carlos de Oliveira estas cicatrizes internalizaram-se, e existem agora numa 
profundidade ameaçadora e inescapável. Ao que seriam aparências de estabilidades, visíveis à superfície, responde o mundo com uma paisagem que está em combustão interna e invisível - mas não menos real. O próprio mundo tornou-se assim caótico, mesmo ao renunciar ao expressionismo ainda de raiz romântica, apreensível em Brandão. Em Carlos de Oliveira é a própria constituição íntima do mundo que é posta em causa. É do lado de dentro da fronteira (na paisagem, que é organização intra-muros) que o próprio sentido se obscurece ao ponto de se tornar inescapável e inatingível, como a consciência. A "casa de adobos" de Carlos de Oliveira, em perigo iminente de derrube, responde assim à "casa" maior e melhor de Campos, como a consciência de uma paisagem oca, minada por dentro de si mesma, e no fundo por si mesma.

Voltemos ao início das observações aqui feitas. Dizia eu que a paisagem é uma forma de evidência do lugar que está longe de se confinar a uma visão idílica dos seus componentes. Por agora, terão ficado claros alguns dos elementos que a compõem: uma fundíssima consciência histórica, que atravessa as representações literárias da paisagem e as transforma de modo indelével; a sua radicação num olhar sobre o humano, desde o início minado por um sentimento de perda que vai acentuando a sua descrença; uma fala a pouco e pouco mais desarticulada e incompreensível; a sua representação como um acontecimento, progressivamente distanciado de uma manifestação sagrada ou religiosa. Dizer que a paisagem literária representa a natureza será certamente verdade, no contexto, se compreendermos que a natureza é, como sempre foi, um acontecimento bumano, um acontecimento perante a consciência do humano. Neste sentido, as paisagens literais ou metafóricas representadas dão conta de diversíssimas formas de o humano se auto-perceber. É na literatura que tal também acontece.

* Ao abrigo do Código de Autor, o presente texto não foi adaptado às regras do novo Acordo Ortográfico, por decisão da Autora. 


\section{BIBLIOGRAFIA}

BAUDELAIRE (1993), As Flores do Mal, Lisboa: Assírio e Alvim.

BRANDÃO, Raul (1983), As Ilhas Desconhecidas. Notas e paisagens, Lisboa: Perspectivas e Realidades.

BUESCU, Helena Carvalhão (1990), Incidências do Olhar. Percepção e representação, Lisboa: Caminho.

(2001), Chiaroscuro. Modernidade e Literatura, Porto: Campo das Letras.

ELIOT, George (1978), Moinho à Beira do Rio, Lisboa: Europa-América.

FRANCASTEL, Pierre (1977), Peinture et société. Naissance et destruction d'un espace plastique - de la Renaissance au Cubisme, Paris, Éd. Denoël.

GARRETT, Almeida (2010), Viagens na Minha Terra, ed. Ofélia Paiva Monteiro, Lisboa, Imprensa Nacional-Casa da Moeda.

HerCulano, Alexandre (2010), in Alexandre Herculano. O Escritor. Antologia, org. António Machado Pires e Maria Helena Santana, Lisboa: Imprensa Nacional-Casa da Moeda.

NOBRE, António (1983), Só, $2^{a}$ ed., Porto: Liv. Civilização Editora.

OLIVEIRA, Carlos de (1992), Finisterra. Paisagem e Povoamento, in Obras de Carlos de Oliveira, Lisboa: Caminho.

PANOFSKY, Erwin (1975), La Perspective comme forme symbolique, Paris, Éd. Minuit.

PESSOA, Fernando (1990), Poemas de Álvaro de Campos, ed. Cleonice Berardinelli, Lisboa: Imprensa Nacional-Casa da Moeda.

QUENTAL, Antero de (1994), Sonetos, org. Nuno Júdice, Lisboa: Imprensa Nacional-Casa da Moeda. 